\title{
Dose-rate dependence of Epitaxial diodes response for gamma dosimetry
}

\section{J. A. C. Gonçalves}

Centro de Tecnologia das Radiações CTR, Instituto de Pesquisas Energéticas e Nucleares IPEN/CNEN Caixa Postal 11049, São Paulo-SP 05422-970, Brazil

Departamento de Física, Pontifícia Universidade Católica de São Paulo

Rua Marquês de Paranaguá 111, São Paulo-SP 01303-050, Brazil

E-mail: josemaryeipen.br

\section{T. C. dos Santos ${ }^{1}$}

Centro de Tecnologia das Radiações CTR, Instituto de Pesquisas Energéticas e Nucleares IPEN/CNEN Caixa Postal 11049, São Paulo-SP 05422-970, Brazil

E-mail: thais_cavalheri@yahoo.com.br

\section{R. F. Barbosa}

Centro de Tecnologia das Radiações CTR, Instituto de Pesquisas Energéticas e Nucleares IPEN/CNEN Caixa Postal 11049, São Paulo-SP 05422-970, Brazil

E-mail: profcelta@hotmail.com

\section{K. C. S. Pascoalino}

Centro de Tecnologia das Radiações CTR, Instituto de Pesquisas Energéticas e Nucleares IPEN/CNEN Caixa Postal 11049, São Paulo-SP 05422-970, Brazil

E-mail: kellypascoalinolyahoo.com.br

\section{C. Bueno}

Centro de Tecnologia das Radiações CTR, Instituto de Pesquisas Energéticas e Nucleares IPEN/CNEN Caixa Postal 11049, São Paulo-SP 05422-970, Brazil

Departamento de Física, Pontifícia Universidade Católica de São Paulo

Rua Marquês de Paranaguá 111, São Paulo-SP 01303-050, Brazil

E-mail: ccbueno@ipen.br

In this work, we present the preliminary results about the evaluation of dose-rate influence on the response of rad-hard epitaxial (EPI) diodes for on-line gamma-ray dosimetry using Co-60 irradiators.

XXXIV edition of the Brazilian Workshop on Nuclear Physics,

Foz de Iguaçu, Parana state, Brasil

5-10 June 2011

1 Speaker 


\section{Introduction}

Silicon detectors have been used for several years in a variety of nuclear and particle physics experiments that require mainly good energy and spacial resolution, high efficiency and fast response [1]. However, ordinary silicon devices present as a major drawback low radiation hardness, being very prone to radiation damage effects which are responsible for a gradual longterm sensitivity decay [2]. This scenario has changed with the development of rad-hard diodes based on magnetic Czockralski (MCz), standard and oxygen-enriched float zone (FZ) silicon substrates [3] which will be used in the tracking system of future colliding beam experiments [4]. The dosimetric characteristics of some rad-hard devices have been investigated in our group in both radiation processing and clinical electron beam dosimetry $[5,6]$. Despite of the higher radiation tolerance of these devices, our results have still shown a sensitivity decay with the dose, attributed to the reduction of the minority carrier lifetime/diffusion length as a function of the dose. Theoretically, at some accumulated dose, the diffusion length becomes comparable with the detector thickness and, for higher doses, the current starts to decrease. This effect can be calculated, but in radiation processing applications the sensitivity loss of the device probably will be stronger than that simulated due to heavy gamma/electron irradiation. This assumption motivated us to investigate the dosimetric characteristics of diodes processed on thin n-type epitaxial layers with high radiation damage tolerance. In this work we present the preliminary results about the evaluation of dose-rate influence on the response of rad-hard epitaxial (EPI) silicon diodes processed at the University of Hamburg [7] as on-line dosimeter in gamma processing using Co-60 irradiators. Some preliminary studies on the radiation damage effects induced in theses diodes are also presented.

\section{Materials and methods}

The diodes used, manufactured by University of Hamburg, were processed on n-type 75 micrometer thick epitaxial silicon layer (nominal resistivity of $69 \mathrm{Ohm} . \mathrm{cm}$ ) grown on a highly doped n-type 300 micrometer thick Czochralski (Cz) silicon substrate (see FIG.1a).
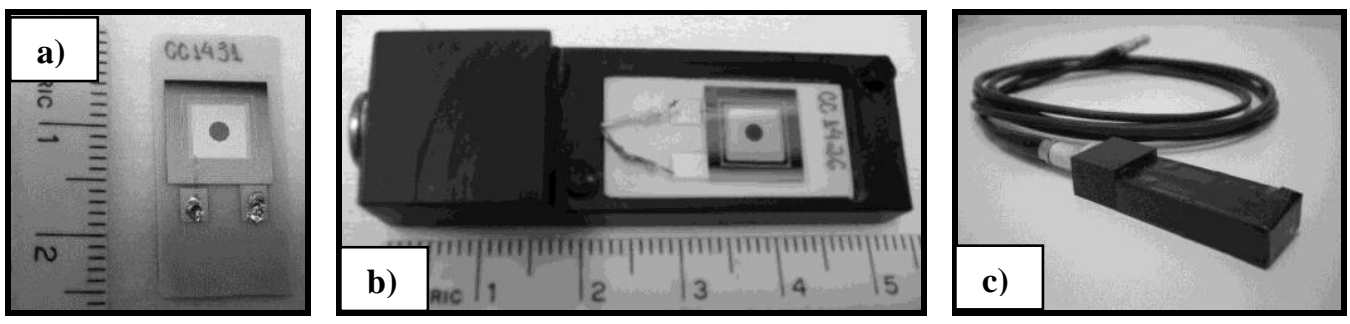

FIGURE 1. a) EPI diode fixed on alumina base; b) EPI diode housed in a PMMA probe; c) The dosimetric probe connected in a LEMO® cable.

Two samples of EPI diodes were investigated: EPI(A) and EPI(B) - both non-irradiated previously. These devices, with $5 \mathrm{~mm} \times 5 \mathrm{~mm}$ active area, were housed in a PMMA probe 
(FIG.1b) and connected (FIG. 1c), in a photovoltaic mode, to a Keithley 617 electrometer. The EPI(A) irradiation was performed in the Radiation Technology Center at IPEN-CNEN/SP using a Co-60 irradiator (Gammacell 220 - Nordion) which delivers a dose rate of $2.16 \mathrm{kGy} / \mathrm{h}$, while the EPI(B) device irradiation was performed in Nuclear Energy Department at UFPE/PE using the same model Co-60 irradiator, but with a dose-rate of $7.47 \mathrm{kGy} / \mathrm{h}$.

During the irradiation, the devices photocurrents were monitored as a function of the exposure time. The diodes were irradiated at room temperature. The dose-response curves of the EPI diodes were achieved through the integration of the current signals as a function of the exposure time.

\section{Results}

The normalized current signals of EPI diodes irradiated with gamma rays are presented in FIGURE 2 as a function of the accumulated dose. This study evidenced a decrease of about $60 \%$ from the initial current for the first $100 \mathrm{kGy}$ dose received for both diodes. This drop is expected once the sensitivity of the diodes falls with the radiation dose [8]. On the other hand, after $500 \mathrm{kGy}$ of exposure, the current signals of the EPI diodes maintain stable.

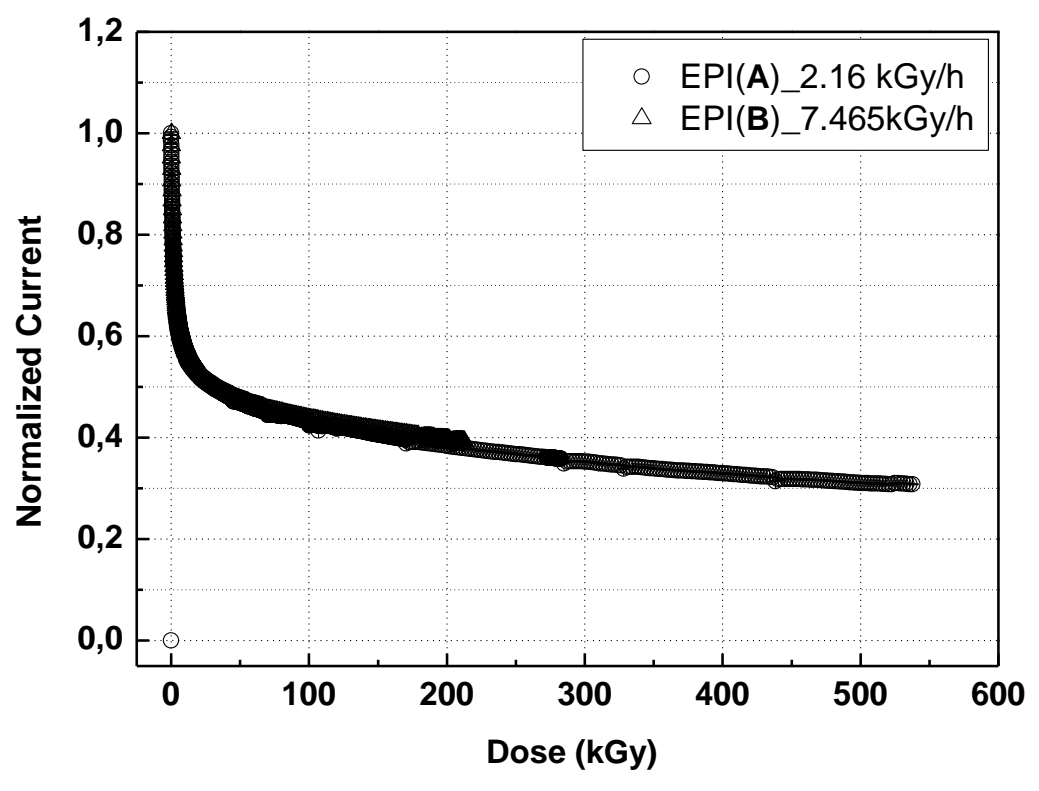

FIGURE 2. Normalized current as a function of dose for EPI(A) and EPI(B) devices. Experimental uncertainties are smaller than the symbols size.

The dosimetric response of the EPI diodes is shown in FIGURE 3. For doses smaller than $550 \mathrm{kGy}$, the curves are well fitted by a second order polynomial function with correlation coefficients of about 0.999 and 0.99991 to EPI(A) and EPI(B) diodes, respectively. 


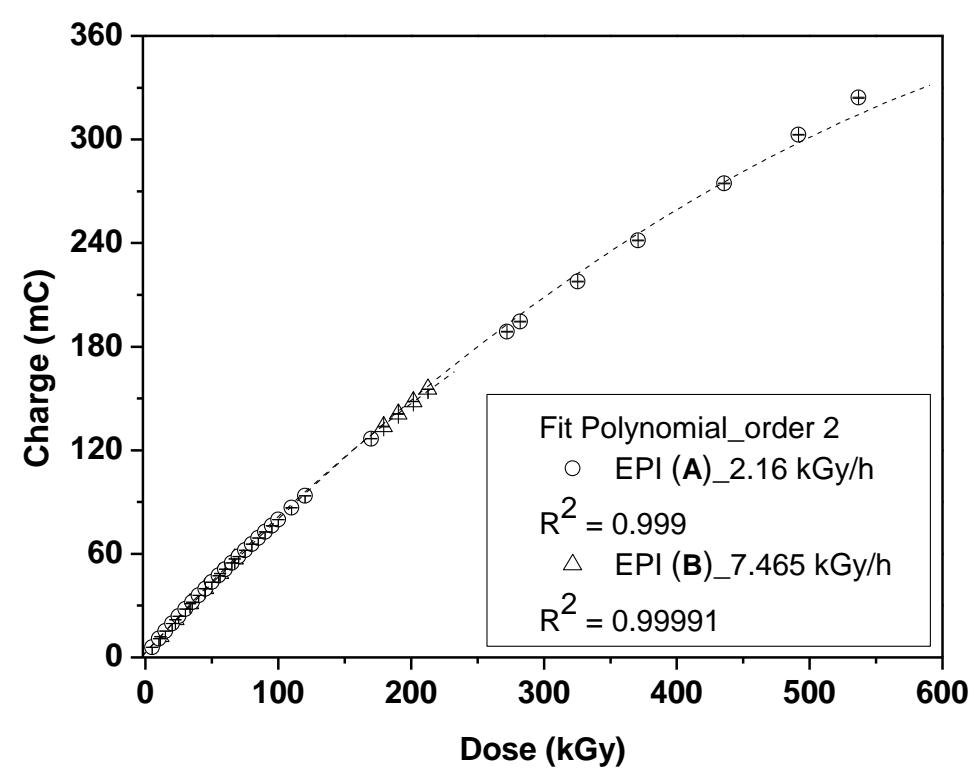

FIGURE 3. Dose-response curves of the EPI diodes for accumulated doses up to $550 \mathrm{kGy}$. Experimental uncertainties are smaller than the symbols size.

\section{Conclusions}

The preliminary results obtained evinced that the EPI diodes response are not dose-rate dependent within the range of $2.16 \mathrm{kGy} / \mathrm{h}$ up to $7.47 \mathrm{kGy} / \mathrm{h}$. On the other hand, the devices studied are tolerant to radiation damages for total absorbed doses of approximately $550 \mathrm{kGy}$ and can be used as reliable alternative on-line dosimeters in high-dose radiation processing.

\section{Acknowledgments}

The authors highly acknowledge Drs. I. Pintilie (Department of Semiconductor Physics and Complex Structures, National Institute of Materials Physics, Romania), G. Lindström and E. Fretwurst (both from University of Hamburg, Germany) for useful discussions and the free supply of the diodes. Prof. Dr. Helen J. Khoury from Physics Department, University of Pernambuco, for the use of Gammacel 220. Thanks are also addressed to E. S. R. Somessari, C. G. da Silveira, S. L. Somessari and H. A. Paes for their indispensable help in radiations at IPEN/CNEN-SP. T. C. dos Santos is grateful to CAPES for the award of a scholarship. This work was partially supported by Conselho Nacional de Desenvolvimento Científico e Tecnológico (CNPq) under contract nº 310493/2009-9.

\section{References}

[1] N. A. Pavel, Particle detectors for biomedical applications-demands and trends, Nucl. Instrum. Meth. A 478 (2002) 1.

[2] S. Pini, M. Bruzzi, M. Bucciolini, E. Borchi, S. Lagomarsino, D. Menichelli, S. Miglio, F. Nava, S. Sciortino, High-bandgap semiconductor dosimeters for radiotherapy applications, Nucl. Instrum. Meth. A 514 (2003) 135. 
[3] J. Harkonen, E. Tuovinen, P. Luukka, H. K. Nordlund, E. Tuominen, Magnetic Czochralski silicon as detector material, Nucl. Instrum. Meth. A 579 (2007) 648.

[4] G. Lindstrom, M. Moll, E. Fretwurst, Radiation hardness of silicon detectors - a challenge from high-energy physics, Nucl. Instrum. Meth. A 426 (1999) 1.

[5] F. Camargo, J. A. C. Gonçalves, H. J. Khoury, C. M. Napolitano, J. Härkönen and C. C. Bueno, $M C z$ diode response as a high-dose gamma radiation dosimeter, Radiat. Meas. 43 (2008) 1160.

[6] T. C. dos Santos, W. F. P. Neves-Junior, J. A. C. Gonçalves, C. M. K. Haddad, J. Harkonen, C. C. Bueno, Use of a Rad-Hard Si diode in clinical electron beam dosimetry, Med. Phys. 37 (2010) 3272 .

[7] G. Lindstrom, I. Dolenc, E. Fretwurst, F. Honniger, G. Kramberger, M. Moll, E. Nossarzewska, I. Pintilie, R. Roder, Epitaxial silicon detectors for particle tracking - Radiation tolerance at extreme hadron fluences, Nucl. Instrum. Meth. A 568 (2006) 66.

[8] G. Rikner and E. Grusell, General specifications for silicon semiconductors for use in radiation dosimetry, Phys. Med. Biol. 32 (1987) 1109. 